\title{
Effect of estrogen given during various periods of prepuberal life on the sexual behavior of rats
}

\author{
SHELTON E. HENDRICKS and MARY WELTIN \\ University of Nebraska at Omaha, Omaha, Nebraska 68132
}

\begin{abstract}
Male and female rats gonadectomized on the day of birth received injections of estradiol benzoate (EB) every other day for 10 days beginning at $2,12,22$, or 32 days of age, or they received no EB. Females were further divided as to whether, at 3 days of age, they were injected with oil vehicle, 5 micrograms testosterone propionate (TP), or 50 micrograms TP. Female behavior was evaluated in response to injected EB and progesterone beginning at 100 days of age, and male behavior was evaluated in response to TP injections beginning at 150 days of age. As frequently reported, TP and EB injected during neonatal life significantly suppressed female behavior in both females and neonatally castrated males. EB given later in prepuberal life was found to complexly influence sexual behavior at adulthood. The findings are discussed with respect to suggestions that ovarian tenancy during prepuberal life can affect the development of female sexual behavior. Also considered is the possibility that changes in the capacity of the developing brain to aromatize androgens into estrogens might account for the finding in that EB, unlike TP, injected after 10 days of age, could suppress female sexual behavior.
\end{abstract}

Much experimentation relating to the growth and differentiation of structures mediating reproductive physiology and sexual behavior has concentrated on the effects of gonadal hormones present during various periods of mammalian development. The potentcy of androgen to influence the course of physiological and behavioral development is clearly demonstrated by experiments in which injections of testosterone propionate (TP) are given neonatally to female rats. Subjects so treated do not ovulate at maturity and do not exhibit normal levels of female sexual behavior (Harris \& Levine, 1965; Barraclough \& Gorski, 1962; and others). Similarly, if the male rat is deprived of androgen by castration prior to 5 days of age, it develops a feminine capacity for receptive behavior (Grady, Phoenix, \& Young, 1965). Estrogen, if injected during neonatal life, acts to inhibit the development of female sexual behavior in female and neonatally castrated male rats in a manner quite similar to androgen (Hendricks, 1969). Thus, the development of female patterns of behavior seems to require that titres of both androgens and estrogens remain relatively low during neonatal life.

The influence on behavioral development of ovarian hormones present after 10 days of age appears more complex. Prepuberal ovarian secretions have been shown to exert a facilitatory influence on the development of female sexual behavior in female and neonatally castrated male rats (Gerall, Dunlap, \&

\footnotetext{
This research was supported by the United States Public Health Service under Grant NS10027. Estradiol benzoate and progesterone were provided by Dr. Preston Perlman of the Schering Corporation and testosterone propionate by Dr. J. J. Chart of Ciba Pharmaceutical Company. The present address for Mary Weltin is 94-055 Anania Drive, Mililani, Hawaii.
}

Hendricks, 1973). Other studies have reported significant effects on female sexual behavior attributable to ovarian tenancy only in neonatally androgenized female rats (Blizard \& Denef, 1973; Hendricks \& Duffy, 1974). However, Napoli and Gerall (1970) reported that injections of estradiol benzoate (EB) begun at 26 days of age had no significant effect on the development of the normal or neonatally androgenized female rat's behavior.

The present study was designed to provide further information about the seemingly complex interactions associated with exposure to ovarian hormones during prepuberal development, and exposure to gonadal hormones during neonatal life. Furthermore, it was designed to give some indication as to whether the behavioral effects reported for prepuberal ovarian tenancy can be ascribed to estrogenic influences. Neonatally ovariectomized female rats were given exogenous estrogen during four different periods of prepuberal life. Additionally, males castrated at birth were similarly exposed to estrogen during development. The homotypical and heterotypical sexual behavior of these animals was assessed at adulthood. It was hypothesized that estrogen injected during the neonatal period (before 10 days of age) would, as previously reported, disrupt the development of female behavior. However, in light of reports of facilitatory influences of ovarian tenancy on the development of female behavior, it was thought that exogenous estrogen might have facilitatory effects when provided later in prepuberal life.

\section{METHOD}

Subjects were $\mathrm{W}$ istar rats born in the laboratory. All subjects were gonadectomized within $24 \mathrm{~h}$ of birth under hypothermia anesthesia. Ovariectomy was accomplished via incisions in the 
Table 1

Number of Subjects in Each Treatment Group

\begin{tabular}{lccccc}
\hline & \multicolumn{5}{c}{ Age of EB Injection (Days) } \\
\cline { 2 - 6 } Neonatal Treatment & No EB & $1-10$ & $10-20$ & $20-30$ & $30-40$ \\
\hline $\begin{array}{l}\text { Oil } \\
\text { Females }\end{array}$ & 12 & 7 & 10 & 8 & 7 \\
$\begin{array}{l}5 \text { micrograms TP } \\
\text { Females } \\
50 \text { micrograms TP }\end{array}$ & 10 & 11 & 11 & 11 & 9 \\
$\begin{array}{l}\text { Females } \\
\text { Day 1 } \\
\text { Castrated males }\end{array}$ & 11 & 10 & 11 & 9 & 6 \\
\hline
\end{tabular}

lateral body walls. orchidectomy through a single midline ventral incision. On Day 3, females received a subcutaneous injection of either $.05 \mathrm{ml}$ corn oil. 5 micrograms TP. or 50 micrograms TP dissolved in a similar amount of oil. Males received oil injections only. Each of the four groups (castrated males, ovariectomized females given oil, 5 or 50 micrograms TP) were divided further into five estradiol benzoate (EB) treatment groups according to the animal's age when EB was administered. Each EB group consisted of animals which were injected subcutaneously with 2 micrograms EB/100 g body weight every other day during one of the treatment periods: $1-10$ days, $10-20$ days, $20-30$ days, or 30-40 days. Also, a group of animals from each neonatal group received no EB. The experimental design and the number of subjects in each treatment group are presented in Table 1 . When subjects were not being injected with the hormone, they received injections of the oil vehicle every other day between birth and $\mathbf{4 0}$ days of age.

At 100 days of age, the subjects began a series of once-weekly mating tests, conducted for 4 consecutive weeks. Each test was preceded by injections with 5 micrograms EB followed in $40 \mathrm{~h}$ by $.5 \mathrm{mg}$ progesterone. Progesterone injections occurred at the beginning of the dark period of the light cycle. Six hours after progesterone administration, each subject was placed in an observation cage containing a vigorous male and was observed until mounted 10 times. Testing was carried out in a glass-fronted semicircular mating arena using dim illumination. Rated components of female receptivity were: degree of lordosis, duration of holding, and presence of darting preceding each mount. Lordosis was assigned a value of: " 0 " when the nonexperimental male mounted and no response occurred: " 1 " when there was a slight lordosis and head lifting; "2" with moderate arching of the entire back and head; and "3" with full arching of the back and sharp tilting of the head. Darting was given the score of " 1 " when occurring before the male mounted. Momentary maintenance of the lordotic posture after the male dismounted was rated as "1." Lordotic postures maintained longer than $1 \mathrm{sec}$ after the male dismounted were scored as "2," A receptivity score was computed for each animal on every mount and summed across the 10 mounts. Body weights were taken weekly beginning at weaning (Day 25). Same-sexed animals were housed five or six to a cage under standard maintenance conditions.

Male behavioral tests began at approximately 150 days of age. Subjects were given injections of 500 micrograms TP every other day throughout the testing period. Four weekly male behavioral tests were conducted. These tests consisted of adapting the subjects to the testing chamber and then introducing an estrous female. Subsequent behaviors were observed for $10 \mathrm{~min}$ and the occurrence of mounts, intromissions. and ejaculations were indicated on an event recorder as they occurred.

\section{RESULTS}

In Figure 1, female behavior for each of the 20 treatment groups is depicted in terms of mean receptivity scores for the four female behavior tests. Five separate analyses of variance, each employing a harmonic mean solution to accomodate unequal cell frequencies, were employed. One analysis (TP injection by EB injection by tests) was applied to the scores of the 15 female groups. A second analysis (EB injection by tests) was applied to the scores of the male subjects. Three additional analyses (sex by EB injection by tests) were used to compare the male groups to each of the neonatal female treatments (oil, 5 micrograms TP and 50 microgram TP). Subsequent to analysis of variance, differences between specific means were tested for statistical significance using the Newman-Keuls procedure. Where appropriate, simple effects contributing to significant interactions were assessed.

The analysis of receptivity scores obtained from the female groups revealed significant main effects attributable to TP injection, $F(2,130)=24.95$, $\mathrm{p}<.01 ;$ EB injections, $F(3,130)=14.97, p<.01$; and tests, $F(3,390)=17.35, p<.01$. These significant effects generally reflect the suppression of receptivity scores by neonatally administered TP and by EB injected $1-10$ or $10-20$ days of age, and the tendency of receptivity scores to increase over tests. Significant interactions were found with TP injection and $E B$ injection, $F(8,130)=3.02, p<.01 ;$ TP injection and tests, $\mathrm{F}(6,390)=2.38, \mathrm{p}<.05$; and $E B$ injection and tests, $F(12,390)=2.36, p<.01$. These significant interactions support the impressions given by Figure 1 that: (a) neonatally injected TP and

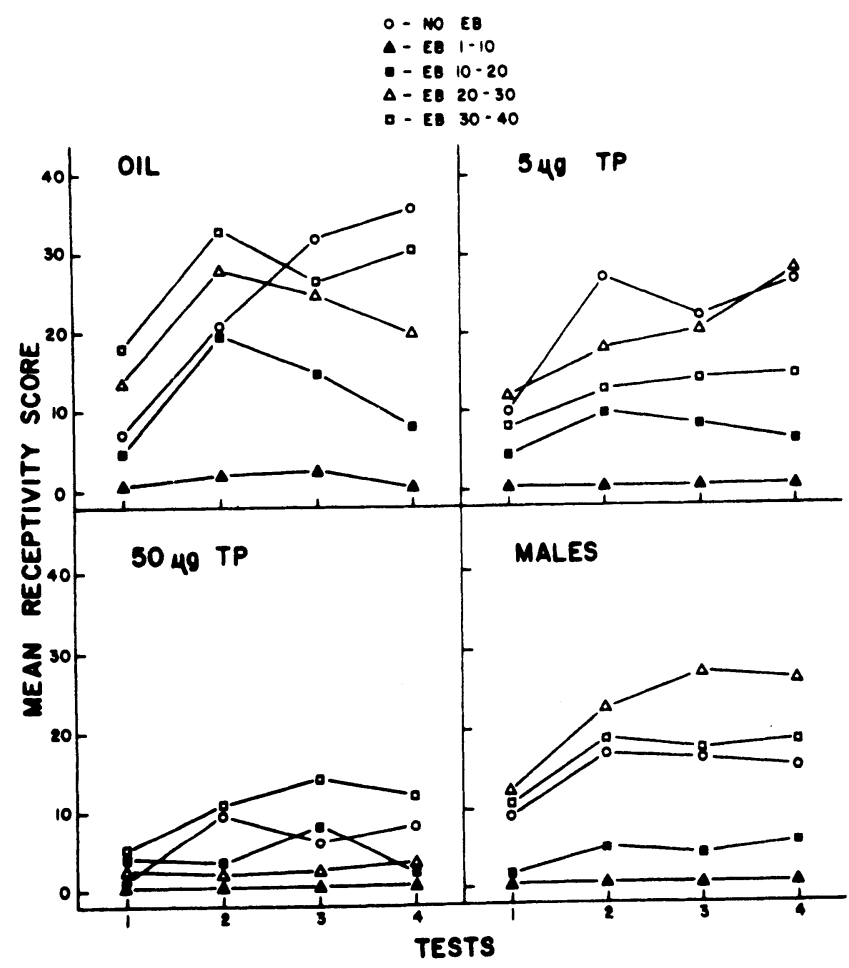

Figure 1. Mean receptivity scores from four female behavior tests for the $\mathbf{2 0}$ treatment groups. 
EB both suppress receptivity scores; (b) EG is effective until 20 days of age, and (c) between-group differences tend to increase over tests.

Generally, EB injections were effective in suppressing receptivity scores only when the animal had not been exposed neonatally to a high dosage of TP. Analysis of the simple effects contributing to the TP injection by EB injection supports this contention. EB injection was found to have significant effects in groups receiving injections of oil at Day 3, $\mathrm{F}(4,39)=8.53, \mathrm{p}<.01 ;$ or 5 micrograms TP, $F(4,48)=6.82, p<.01$; but not in the case of groups injected with 50 micrograms TP at 3 days of age, $\mathrm{F}(4,43)=1.94, \mathrm{p}>.05$.

Only the 50-microgram dosage of TP was effective in suppressing receptivity scores. The Newman-Keuls analysis revealed that those groups injected with 50 micrograms TP exhibited significantly lower receptivity scores than either the oil-injected groups, $\mathrm{p}<.01$, or the groups injected with 5 micrograms TP, $p<.01$. The groups receiving injections of oil or 5 micrograms TP were not significantly different from each other.

With respect to the $E B$ injection variable, the Newman-Keuls analysis revealed that receptivity scores were suppressed by EB injected 1-10 or $10-20$ days of age. Both treatments resulted in significantly lower receptivity scores than treatments involving no EB. Groups receiving EB injections at 20-30 days or 30-40 days of age did not differ significantly from each other or from the groups receiving no EB. Further comparisons revealed no significant differences between groups receiving EB injections at either 10-20 days of age or 20-30 days of age. These groups were not significantly different from those receiving no EB. However, the groups injected with EB at 30-40 days of age did have higher receptivity scores than those groups injected with EB at 10-20 days of age.

Because of the significant interactions among the variables and tests, further analyses were employed to specify the exact nature of treatment effect differences. Comparing receptivity scores from the first female behavior test for the neonatal TP groups, it was found that subjects who received EB at $30-40$ days of age exhibited significantly higher scores, $\mathrm{p}<.01$, than subjects receiving no EB. However, this facilitation of female sexual behavior was not evident in subsequent tests. Also, the group receiving EB injections at 10-20 days of age showed a change over tests in its relationhship with another group. This group, on the first two tests, did not exhibit receptivity scores significantly different from those without EB injections; however, the difference between these groups was significant for Test 3 and Test $4, p<.01$. Considering those groups which received 5 micrograms TP at 3 days of age, there is some indication from Figure 1 that EB injected at 30-40 days of age may have suppressed receptivity scores relative to the group receiving no $\mathrm{EB}$. However, the difference between these groups barely attains statistical significance, $p<.05$. For those groups receiving 50 micrograms TP at 3 days of age, there were no significant simple effects or interactions with tests.

Analysis of variance applied to receptivity scores obtained from male groups revealed statistically significant main effects attributable to EB injection, $F(4,53)=13.28, p<.01$ and tests, $F(3,159)=8.03$, $\mathrm{p}<.01$. As was the case with females, EB injections at 1-10 days of age and 10-20 days of age resulted in significantly lower receptivity scores, $p<.01$, compared to $E B$ injections at a later age or no $E B$. In contrast to the data obtained from females, there was a clear facilitatory effect on female sexual behavior of EB injected at 20-30 days of age. The mean receptivity score for this group was significantly higher than that for the group receiving no EB, $p<.01$, or the group receiving EB at $30-40$ days of age, $p<.05$.

The receptivity scores exhibited by the various treatment groups are depicted in a different manner in Figure 2. In this figure, only receptivity scores for the fourth behavioral test are plotted for each TP injection condition as a function of EB injection. This figure provides a clearer picture of some of the interactions between these variables.

The analysis comparing the males to the oil-injected females revealed that these females exhibited significantly higher receptivity scores, $F(1,92)=$ $12.45, \mathrm{p}<.01$. There were also significant effects attributable to $E B$ injection, F)4,92) $=21.45$, $\mathrm{p}<.01$, and tests, $F(3,276)=16.79, \mathrm{p}<.01$. The interaction of $E B$ Injection by Tests was also significant, $F(12,276)=1.92$, $p<.05$. A comparison between neonatally castrated males and females

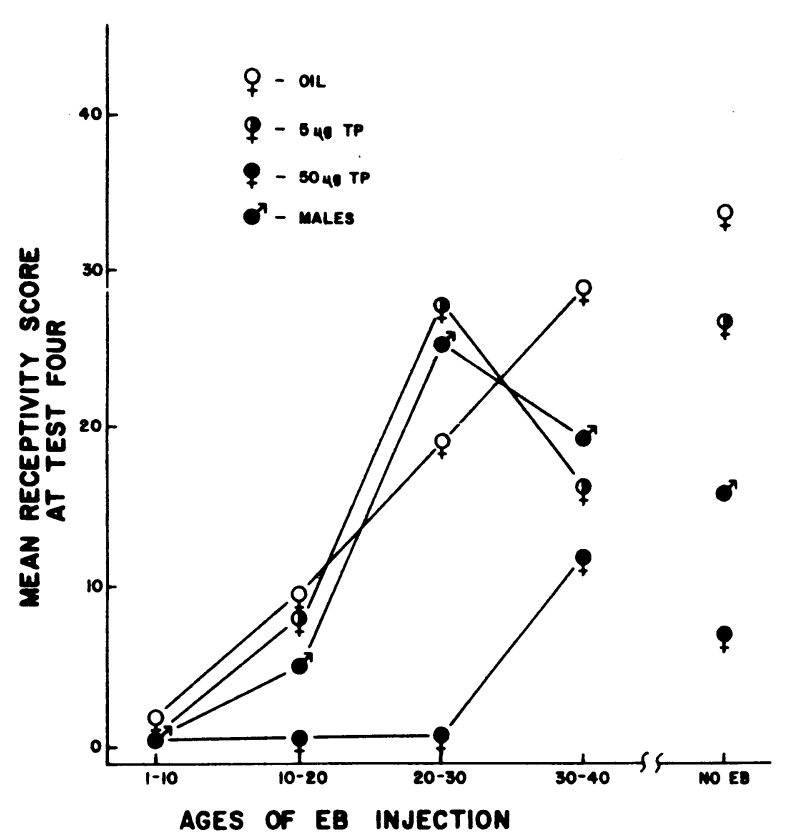

Figure 2. Mean receptivity scores for the fourth female behavior test. 
Table 2

Percentage of Subjects Exhibiting Female Behavior

\begin{tabular}{lcrccc}
\hline & \multicolumn{5}{c}{ Age of EB Injection (Days) } \\
\cline { 2 - 6 } Neonatal Treatment & No EB & $1-10$ & $10-20$ & $20-30$ & $30-40$ \\
\hline $\begin{array}{l}\text { Oil } \\
\text { Females }\end{array}$ & 100.00 & 20.00 & 70.00 & 100.00 & 100.00 \\
$\begin{array}{l}5 \text { micrograms TP } \\
\text { Females }\end{array}$ & 100.00 & .00 & 45.46 & 100.00 & 87.78 \\
$\begin{array}{l}50 \text { micrograms TP } \\
\text { Females }\end{array}$ & 75.00 & .00 & 50.00 & 30.00 & 50.00 \\
$\begin{array}{l}\text { Day 1 } \\
\text { Castrated males }\end{array}$ & 100.00 & 19.16 & 46.26 & 100.00 & 92.31 \\
\hline
\end{tabular}

receiving 5 micrograms TP at 3 days of age showed no significant difference in receptivity scores. Again, EB injection had a significant effect, $F(4,101)=17.08$, $p<.01$ and between-test comparisons produced significant interaction was between EB injection and tests, $F(13,303)=2.44, p<.01$. Significantly higher receptivity scores, $F(1,96)=21.17, p<.01$, were obtained for the males as compared to the females injected with 50 micrograms TP at 3 days of age. The effects of EB injection, $F(4,96)=8.86, p<.01$, and the interaction of Sex by EB Injection, $F(4,96)=$ $6.61 . p<.01$ were found to be statistically significant.

One striking characteristic of the data seen in Figures 1 and 2 , not brought out by the foregoing analyses, is the extremely potent effect of EB injected at 1-10 days of age. This treatment, particularly when combined with neonatal androgenization or when given to males, almost totally abolished any evidence of female behavior under the testing conditions employed in the present study. However, some of these differences were not statistically significant as in the receptivity score comparison between females injected neonatally with 50 micrograms TP who received either EB injections at 1-10 days of age or no EB injections. This subjective impression, however, is supported if one looks at whether or not the subject exhibited any female sexual behavior over the four female behavior tests (receiving a receptivity score of greater than " 0 " on any one test). The percentages of subjects in each group exhibiting sexual behavior are presented in Table 2. If one only considers whether or not a subject's total receptivity score is greater than " 0 ," one finds that $75 \%$ of the females injected neonatally with 50 micrograms TP and not given EB at 1-10 days of age did so. The difference in the frequency of receptivity scores greater than " 0 " between these two groups is significant by the Wilcoxon sign test, $\mathrm{p}<.01$. Also, the difference between the female groups given 5 micrograms TP at 3 days of age and receiving either EB at 1-10 days of age or at 10-20 days of age was significant using this alternative measure of female sexual behavior, $p<.01$, but not so when receptivity scores were analyzed.
In addition to analyzing receptivity scores, analyses of variances were performed using each of the components of this measure (lordosis, holding, darting) as dependent measures. Generally, the same significant differences were seen as when using receptivity scores. The data were also analyzed in terms of lordosis quotient: The number of times the subject lordosed divided by the number of times it was mounted. This analysis also revealed the same pattern of differences as seen with receptivity scores.

The data obtained from tests for male behavior are presented in Table 3. Here the data are depicted in terms of total male responses: mounts, mounts with intromission patterns and ejaculatory responses for the four tests. In no instance did any subject exhibit an ejaculatory response; thus the data in Table 3 represent only the total number of mounts, with and without intromission. An analysis of variance run on these data for all groups revealed no significant between-group differences. The only statistically significant effect was attributable to tests, $F(3,532)=$ 63.97, $\mathrm{p}<.01$. There were no significant interactions. Analysis of only those responses in which the intromission pattern was observed also revealed no significant between-group difference.

\section{DISCUSSION}

The present study confirms again the now extensively reported effects on female sexual behavior of gonadal hormones present during the perinatal life of the rat. In the case of TP, the current study provides a clear demonstration of a dosage-dependent suppression of female sexual behavior. The greater capacity of EB to suppress female sexual behavior is also in evidence. Either by its greater potency or because it was continually injected, the EB injections given between birth and 10 days proved to be the most effective treatment with respect to the suppression of female sexual behavior. The average total dosage of EB given would be a little under .10 micrograms. Gerall et al. (1973) demonstrated that such a dosage was sufficient, when administered at 3 or 6 days of age, to severely suppress the capacity of the neonatally

Table 3

Mean Total Mounts for Four Behavior Tests

\begin{tabular}{lccccc}
\hline & \multicolumn{5}{c}{ Age of EB Injection (Days) } \\
\cline { 2 - 6 } Neonatal Treatment & No EB & $1-10$ & $10-20$ & $20-30$ & $30-40$ \\
\hline $\begin{array}{l}\text { Oil } \\
\text { Females }\end{array}$ & 23.14 & 12.75 & 19.50 & 19.54 & 16.04 \\
$\begin{array}{l}5 \text { micrograms TP } \\
\text { Females }\end{array}$ & 32.80 & 11.44 & 26.72 & 10.73 & 16.87 \\
$\begin{array}{l}50 \text { micrograms TP } \\
\begin{array}{l}\text { Females } \\
\text { Day 1 }\end{array}\end{array}$ & 26.44 & 18.82 & 10.71 & 25.88 & 16.49 \\
Castrated males & 18.45 & 23.39 & 18.77 & 29.97 & 29.20 \\
\hline
\end{tabular}


castrated male rat to exhibit female sexual behavior. Our current findings demonstrate that the potency of this treatment is not diminished by spacing the hormone's administration through the first 10 days of life. Rather, it would appear that is suppressive effects of female sexual behavior are enhanced. While 50 micrograms TP injected without any subsequent EB injection did greatly suppress female behavior, $75 \%$ of the subjects did exhibit some female sexual behavior. By contrast, of those groups receiving EB injections between 1 and 10 days of age, the highest rate of exhibiting any female sexual behavior was only $20 \%$. Single injections of EB, while suppressing female sexual behavior, have not, under conditions of testing very similar to those employed here, resulted in the total absence of the behavior (Hendricks, 1969; Levine \& Mullins, 1964). The greater potency of steroids present for longer periods of neonatal life is suggested by the reports that injection of androgen into 2-day-old female hamsters in silastic pellets, which release the hormone slowly, greatly enhanced the capacity of androgens to suppress the development of female sexual behavior (Murray \& Farrell, Note 1) and that the neonatal administration of longer acting forms of steroids are more effective in suppressing female behavior than more rapidly metabolized forms (Whalen \& Edwards, 1967).

A suppressive effect of EB on female behavior was also evident when EB was injected between 10 and 20 days of age. Beach, Noble, \& Orndoff (1969) reported no significant influence on the female sexual behavior of neonatally castrated males by injection of 200 micrograms TP at 13 and 14 days of age. Also, Hendricks (1972) found that neither 10 micrograms TP nor 500 micrograms TP injected every other day between 14 and 60 days of age had an effect on the female sexual behavior of the neonatally castrated male. In the present study, much smaller amounts of EB (.10-.20 micrograms) injected $12,14,16,18$, and 20 days of age were found to severely suppress, and in many cases abolish, the capacity to exhibit female sexual behavior in neonatally castrated male and female rats. Thus, while the effects of TP injection seem limited to the period before 10 days of age, the critical period for development of sexual behavior in the rat extends beyond 10 days of age in terms of the capacity of EB to modify the course of development. Current data relating to the capacity of the mammalian central nervous system to aromatize androgens into estrogens (Naftolin, Ryan, \& Petro, 1972) and the hypothesis that it is estrogen or its metabolites which are critical for the masculinization of neural tissues which mediate female sexual behavior (Coniglio, Paup, \& Clemens, 1973), suggest one possible explanation for the extended influence of EB on the development of female sexual behavior. Specifically, the ease at which the young rat brain makes the androgen-estrogen conversion may decrease as a function of age. After 10 days of age, the female brain may well be sensitive to the masculinization effects of estrogens, but the capacity of the brain to convert androgens to the effective estrogens may have diminished to the point that androgens are no longer effective. The direct administration of estrogens would preclude the necessity of conversion and masculinize the still-sensitive tissue. Evidence for a much lesser capacity of the adult rat brain to aromatize androgens compared with the perinatal tissues has been presented by Reddy, Naftolin, \& Ryan (1974). If one assumes conversion of androgens to estrogens to be important for sexual differentiation of neural tissues, the contrasting effects of TP and EB injected after 10 days of age could be accounted for by a decrease with age in the rate of aromatization in the brain.

Comparing the receptivity scores of neonatally castrated males to the female groups also supports previous reports. When measures similar to those employed in the present study are used, such males have been found to exhibit slightly less female behavior than normal females and more female behavior than females injected neonatally with relatively high dosages of TP (Hendricks, 1969). A similar pattern of differences was seen in the present study. The comparability of the neonatally castrated male to the female receiving relatively low dosages of TP neonatally seen in our data has also been noted in previous work (Dunlap, Gerall, \& Hendricks, 1972).

Data obtained from groups receiving EB injections later than 20 days of age do provide some evidence for a facilitatory effect of exogenous estrogen on the development of female sexual behavior. However, the results are neither simple nor easily interpretable. The most consistent finding with respect to the influence of ovarian tenancy on the development of the capacity to exhibit female sexual behavior is in the case of the neonatally castrated male. Three studies have shown that such males provided prepuberally with ovarian implants exhibit, at maturity, more female behavior than males not receiving ovarian implants (Dunlap, Gerall, \& McClean, 1973; Gerall, Dunlap, \& Hendricks, 1973; Hendricks \& Duffy, 1974). The current finding that EB injected into neonatally castrated males between 20 and 30 days of age facilitates the development of female sexual behavior can be viewed as being consistent with the reports of ovarian effects. Gerall et al. (1973) found the strongest effect of prepuberal ovarian tenncy in females during initial behavior tests. In the present study, females injected with oil at 3 days of age and receiving EB injections between 30 and 40 days of age did show higher receptivity scores on the initial tests when compared to those subjects receiving no EB. Similar to the findings of Gerall et al. )1973) with respect to ovarian tenancy, these differences are absent in the later tests. Thus, the present study does provide some support for the hypothesis that the reported effects of ovarian tenancy on the 
development of female sexual behavior can be ascribed to estrogenic influences.

The major inconsistency between the effects of exogenous estrogen and endogenous influences of the ovary on behavioral development is with respect to the androgenized female. Previous studies have demonstrated, also, that ovarian tenancy facilitates the development of female sexual behavior in neonatally androgenized females (Blizard \& Denef, 1973; Hendricks \& Duffy, 1974). A more recent replication of this finding is also available (Nikels, Note 2). There was no significant facilitatory effect on receptivity scores produced by EB injection to neonatally androgenized females in the present study. This finding is consistent with the report of Napoli and Gerall (1970) that EB administered from 26 days of age had no effect on the sexual behavior of control or neonatally androgenized female rats. However, neither the present data nor the findings of Napoli and Gerall preclude the possibility that, with appropriate dosages and timing, the effect of prepuberal ovarian tenancy on androgenized females could be duplicated by exogenous estrogen.

The absence of any effect of the neonatal hormonal manipulation on male sexual behavior is inconsistent with some previous reports (Hendricks, 1969; Levine \& Mullins, 1964, and others). However, studies do report no effect of these treatments on male sexual behavior (Whalen \& Edwards, 1967). In the present study, the variability within treatment groups was quite high, and there were no consistent patterns in the data. Generally, those studies reporting effects upon male sexual behavior consequent to variations in the perinatal hormone manipulation administered higher dosages than those used in the present study.

\section{REFERENCE NOTES}

1. McMurray, M., \& Farrell, A. The effects of androgens administered neonatally in silastic on female sexual behavior in the goldn hamster. Paper presented at the meeting of the Eastern Regional Conference on Reproductive Behavior. Atlanta, June 1974.

2. Nikels, K. W. Ovarian influences on neonatal androgenization of the female rat. Paper presented at the meeting of the Rocky Mountain Psychological Association, Salt Lake City, May 1975.

\section{REFERENCES}

BARRAClOUGH, C. A., \& Gorski, R. Studies on mating behavior in the androgen sterilized female rat in relation to the hypothalamic regulation of sexual behavior. Journal of Endocrinology, 1962. 25. 175-182.

BeAch, F. A., Noble, R. G., \& ORndoff, R. K. Effects of perinatal androgen treatment on responses of male rats to gonadal hormones in adulthood. Journal of Comparative and Physiological Psychology, 1969, 68, 490-497.

Blizard, D., \& Denef, C. Neonatal androgen effects on open-field activity and sexual behavior in the female rat: The modifying influence of ovarian secretions during development. Physiology and Behavior, 1973, 11. 65-69.

Coniglio, L. P., Paup, D. C., \& Clemens, L. G. Hormonal factors controlling the development of sexual behavior in the male golden hamster. Physiology and Behavior, 1973. 10. 1087-1094.

Dunlap. J. L.. Gerall, A. A., \& McLean, L. D. Enhancement of female receptivity in neonatally castrated males by prepuberal ovarian transplants. Physiology and Behavior, 1973, 10, 701-705.

Dunlap, J. L.. Gerall, A. A., \& Hendricks, S. E. Female receptivity in neonatally castrated males as a function of age and experience. Physiology and Behavior, 1972, 8, 21-23.

Gerall, A. A., Dunlap, J. L., \& Hendricks, S. E. Evaluation of ovarian secretions on female behavioral potentiality in the rat. Journal of Comparative and Physiological Psychology, 1973, 82. 449-465.

Gerall, A. A., Hendricks, S. E., Johnson, L., \& Bounds, T. Evaluation of the effects of early castration in male rats on adult sexual behavior. Journal of Comparative and Physiological Psychology, 1967, 64, 206-212.

Grady, K. L., Phoenix, C. H., \& Young, W. C. Role of the developing rat testis in differentiation of neural tissue mediating behavior. Journal of Comparative and Physiological Psychology, 1965, 59, 176-182.

Harris, G. W., \& Levine, S. Sexual differentiation of the brain and its experimental control. Journal of Physiology, 1965, 181, 379-400.

HENDRICKS, S. E. Influence of neonatally administered hormones and early gonadectomy on rats' behavior. Journal of Comparative and Physiological Psychology, 1969, 69, 408-413.

HENDRICKS, S. E. Androgen modification of behavioral responsiveness to estrogen in the male rat. Hormones and Behavior, 1972, 3, 47-54.

Hendricks, S. E., \& Duffy, J. A. Ovarian influences on the development of sexual behavior in neonatally androgenized rats. Developmental Psychobiology, 1974, 7, 297-303.

LEViNe, S., \& Mullins, R. F. Estrogen administered neonatally affects adult sexual behavior in male and female rats. Science, 1964, 144, 185-187.

Naftolin, F., Ryan, K. J., \& Petro, Z. Aromatization of androstenedione by the anterior hypothalamus of adult male and female rats. Endocrinology, 1972, 90, 295-298.

Napoli, A. M., \& Gerall, A. A. Effect of estrogen and anti-estrogen on reproductive function in neonatally androgenized rats. Endocrinology, 1970, 87, 1330-1337.

Reddy, V. V. R., Naftolin, F., \& Ryan, K. J. Conversion of androstenedione to estrone by neural tissues from fetal and neonatal rats. Endocrinology, 1974, 94, 117-121.

Whalen, R. E., \& Edwards, D. A. Hormonal determinants of the development of masculine and feminine behaviour in male and female rats. Anatomical Record, 1967, 157, 173-180.

(Revision received and accepted for publication October 9, 1975.) 